"نشريه علوم زراعى ايران"

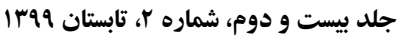

مقاله يُوهشى

انتقال يذيرى نشانكر هاى ريزماهواره جو براى ارزيابى روابط زنتيكى در خويشاوندان وحشى كندم جنس هاى Triticum و

Transferability of barley microsatellite markers for assessing genetic relationships of wheat wild relatives of Triticum and Aegilops genera

$$
\text { احمد احمدى لكى '، سيدابو القاسم محمدى '، محمد مقدمّّو مصطفى وليز اده؟ }
$$

$$
\text { جكيده }
$$

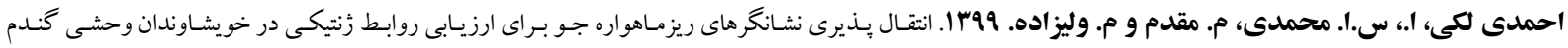
جنس هاى Aegilops و Triticum نشريه علوم زراعى ايران. rr(Y): ITY-10r.

زنوميك مقايساى همخطى بين زنوم كونهاى خويشاوند نزديك كياهى را با دقت بالايى نشان داده و امكسان تبـادل نشـانكرها

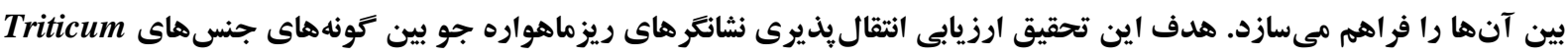

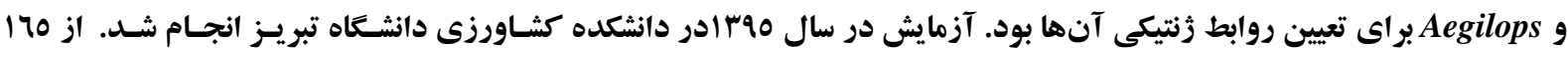

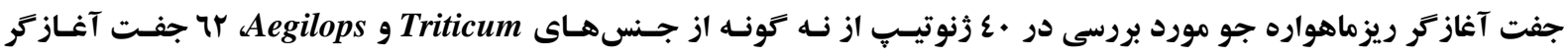

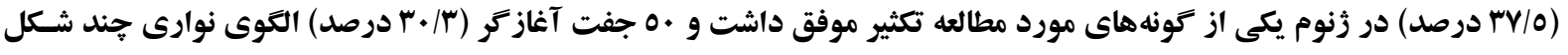

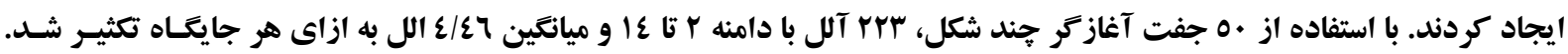

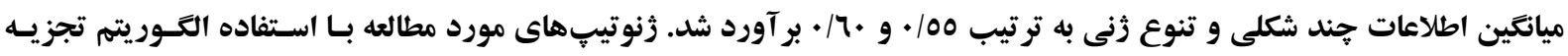
خوشاى و ضريب فاصله تكاملى به جهار كروه تفكيك شدند. كونههاى جـنسهـاى Ariticum و Aegilops در دو كـروه جداكانسه قرار كرفته و در داخل هر جنس نيز كروهبندى با ساختار زنوم آنها تطابق داشت. در تجزيه به بردارهـاى اصـلى، دو بـردار اصلى لى

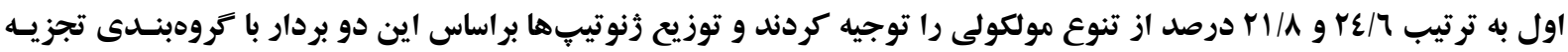
خوشهاى مطابقت داشت. نتايج اين آزمايش نشان داد كه از نشانكرهاى انتقال يذير جو مسى تـوان بـا موفقيست در مطالعـات زنتيكسى و بهنزادى در كندم و خويشاوندان آن استفاده كرد.

وازههاى كليدى: انتقال يذيرى، تنوع زنتيكى، جو، خويشاوندان وحشى كندم و نشانكر هاى ريزماهواره.

\footnotetext{
اين مقاله مستخرج از رساله كارشناسى ارشد نغارنده اول مىباشد

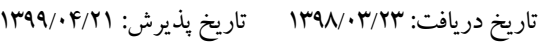

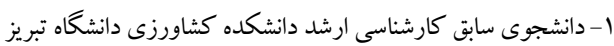

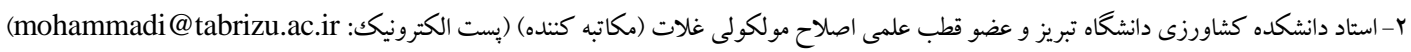

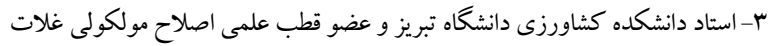

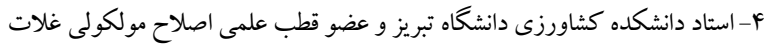


هستـند. ايسن آلـلـهـاى مفيــد در ارقـام امسروزى كنــدم

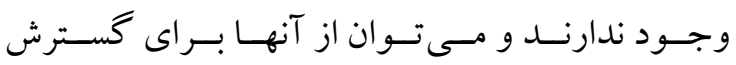

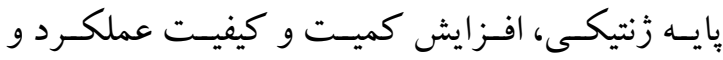

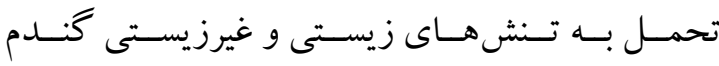

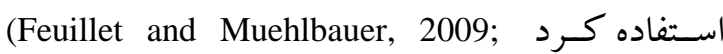
Hovhannisyan et al., 2011; Lina et al., 2012)

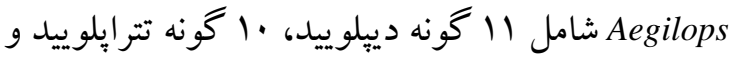

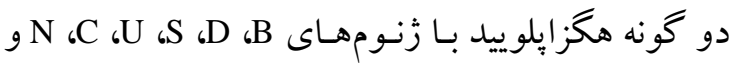

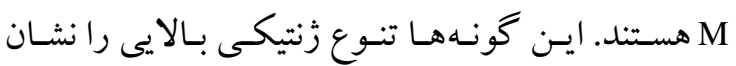

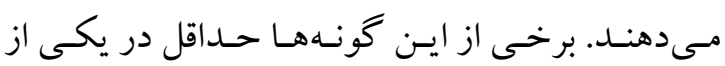

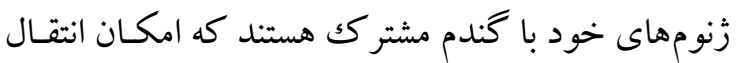

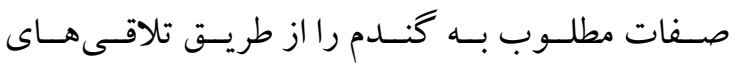

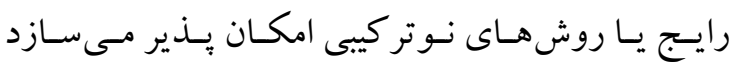
(Schneider et al., 2008)، بنابر اين مطالعه تنوع و رابطـه دئه زنتيكى بين گونهاى جـنس هـاى Triticum و Aegilops

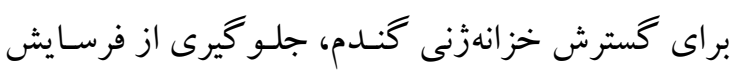

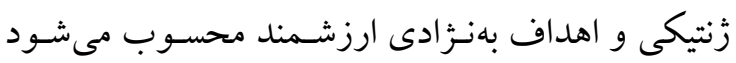
.(Lina et al., 2012)

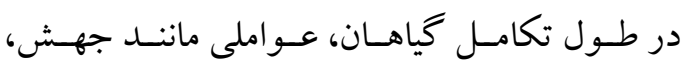

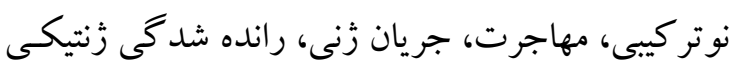

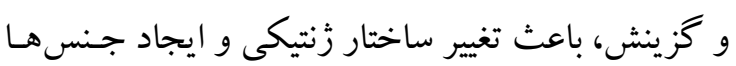

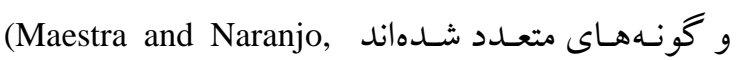
2000; Feuillet and Muehlbauer, 2009)

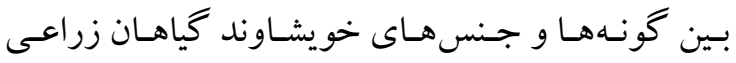

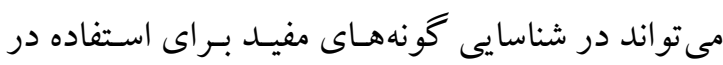

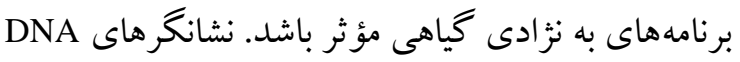

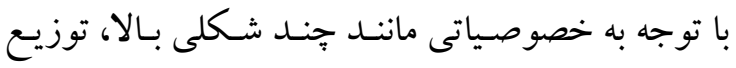

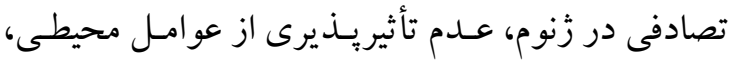

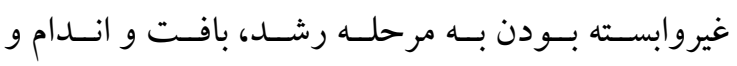

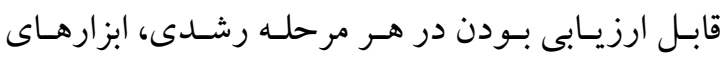

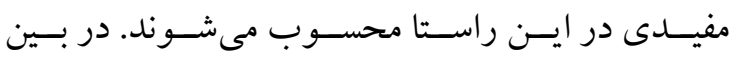

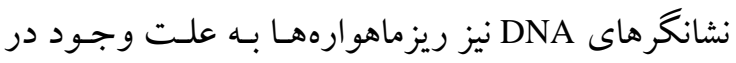

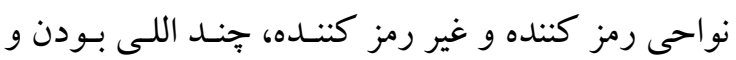

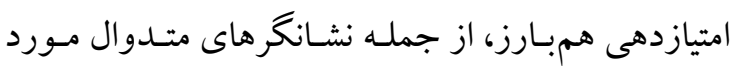

\section{مقدمه}

جايكزينى تو دههاى بومى با ارقام اصلاح شده جديد

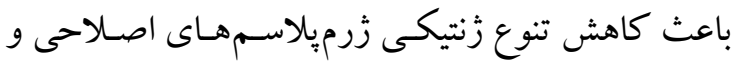
فرسايش زنتيكى در آنها شده است. بـا توجـه بـهـ تغييـر

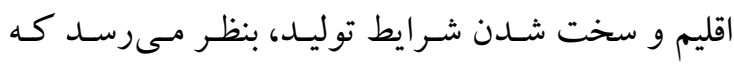

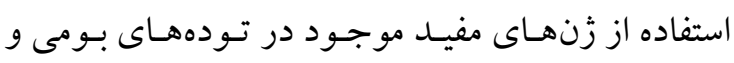

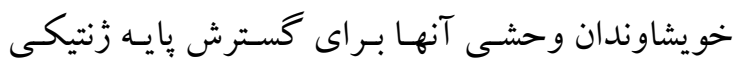

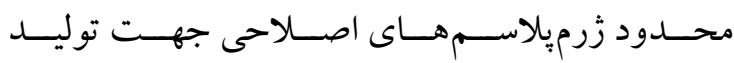

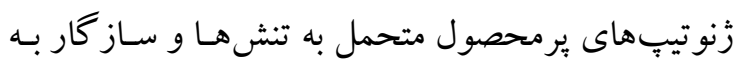
شرايط تغيير اقليم ضرورى است (Tilman et al., 2011).

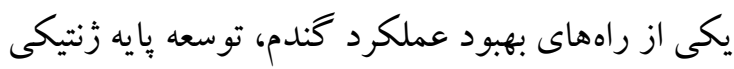

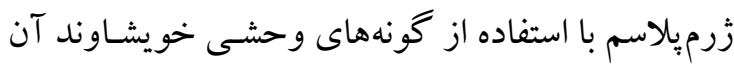

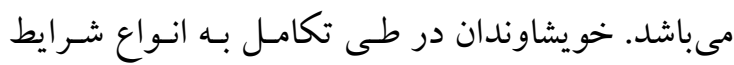

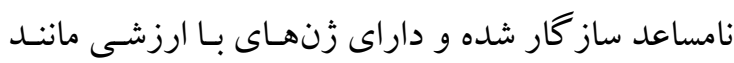

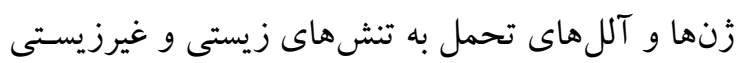

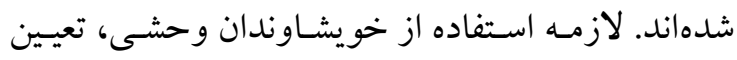

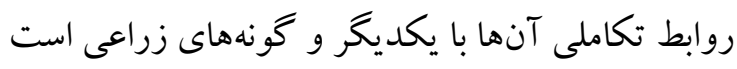

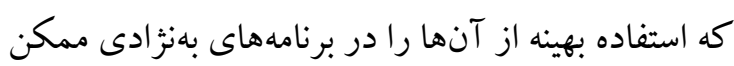
مسىسـازد Colmer et al., 2006; Feuillet and .Muehlbauer, 2009)

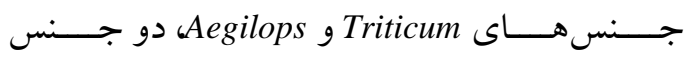

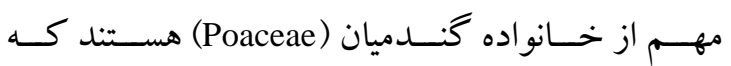

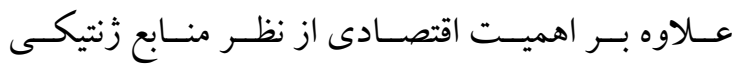

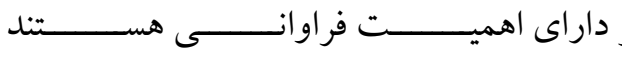

.(Feuillet and Muehlbauer, 2009; Lina et al., 2012) سـAe. tauschii وAe. speltoides ،T. urartu

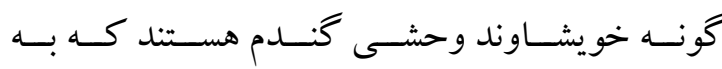
Huang et al., 2002; ) A ترتيـب اجسداد زنسومهــاى Rodriguez-Suarez et al., 2011 Miki et al., 2019; Safari and Mehrabi, ) B زنسوم

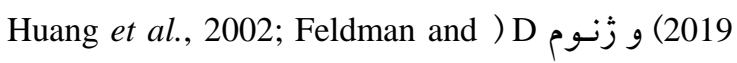
(Levy, 2005; Gororo et al., 2002 امروزى معرفى شدهاند. علاوه بر اين، گونههاى ايسن دو

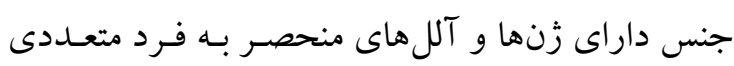




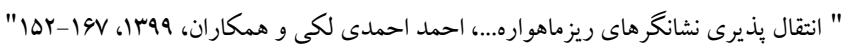

و 1995; Kuleung et al., 2004; Yildirim et al., 2009) و و از ريز ماهوارههـاى (Yildirim et al., 2009) A. sativa جو در گونهـاى Castillo et al., 2010) H. chilense)، T. aestivum ،(Yildirim et al., 2009)A. sativa (Holton et al., 2002; Varshney et al., 2005; O. sativa $S$. cereale ، Yildirim et al., 2009) (Varshney et al., 2005) هدف اين تحقيق، بررسى روابط تكاملى گونسههـاى

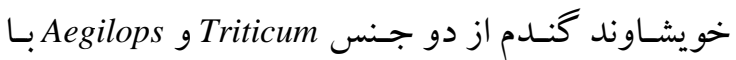
استفاده از نشانگر هاى ريزماهواره جـو و بــر آورد ميـزان انتقال يذيرى و جندشـكلى نشـانكر هاى ريزمـاهواره جـو در كونهاى اين جنس ها بوده است.

\section{مواد و روشها}

اين آزمايش در سال هوسا در دانشـده كشـاورزى لير دانشخاه تبريز انجام شد. مواد گياهى مورد مطالعه شـامل

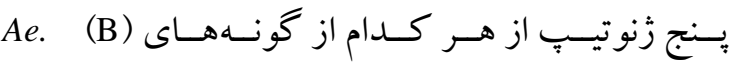
Ae. (U) ‘Ae tauschii Coss. (D) sspeltoides Tausch. Ae. ( $\left(\mathrm{D}^{\mathrm{c}} \mathrm{M}\right)$, Ae. triuncialis L. (UC) ،ambellulata

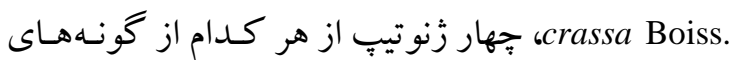
T. boeoticum $\left(\mathrm{A}^{\mathrm{b}}\right)$ ‘Ae. columnaris Zhuk. (UM) Boiss. T. urartu (A $\left.{ }^{\mathrm{u}}\right)$

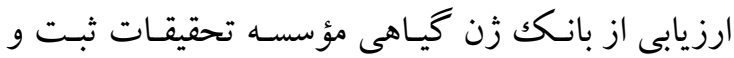
كو اهى نهال و بذر كرج تهيه شد.

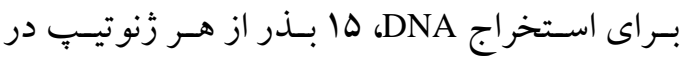

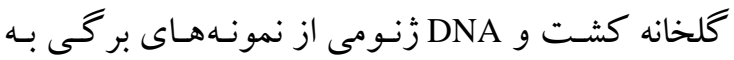
روش CTAB (Saghai Maroof et al., 1984) شد. كيفيت و كميت DNA نمونهها به ترتيب با اسـتفاده از زل آخــارز ^/ • درصسـد و اســكتروفتومتر تعيـين و براى استفاده در واكنش زنجيرهاى يلى مراز، نمونههـاى

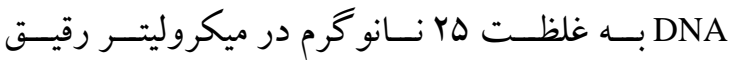

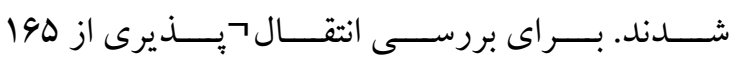
جفت آغاز
اسـتفاده هسـتند (Oliveira et al., 2006). مطالعـات

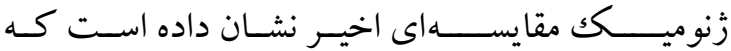

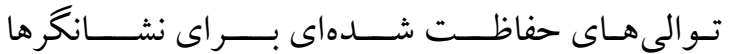
و زنهـــا در موقعيــت مشــــابه زنـــوم كونــهـهــــاى

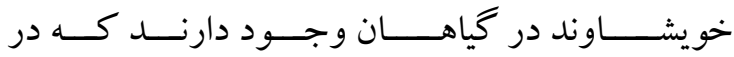

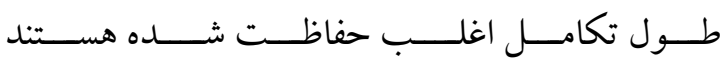
(Andrew et al., 2000; Castillo et al., 2010)

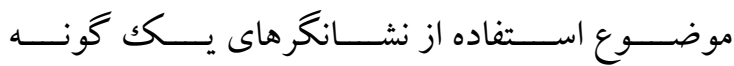

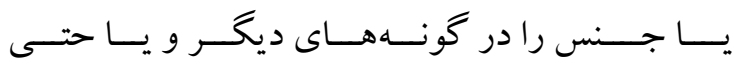

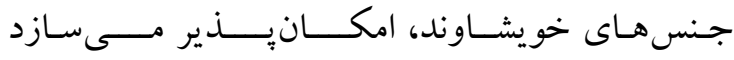
(Adonina et al., 2005; Yildirim et al., 2009; Castillo et al., 2010) در اغلـب مـوارد بـه علـت عـدم وجـود . d.

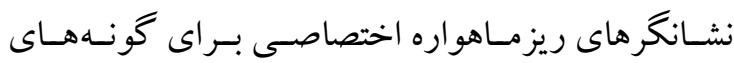
وحشى، از نشانكر هاى گونههـاى زراعى در گونسهــا و حتى جنس هاى خويشاوند نزديكك استفاده مسى شـود. بـــ

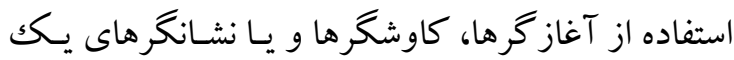

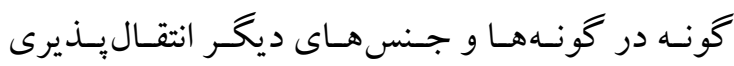
اطلاق مسىشـود. بررسى تـو الىهـاى (Transferability) زَنومى كندم و جو نشاندهنده همولوزى كافى بسين ايسن زنومها در نواحى احاطه كننده جايخاههـاى ريزمـاهواره مىباشـــ، بنـابراين در مطالعـات مختلـف از نشـانكر هاى

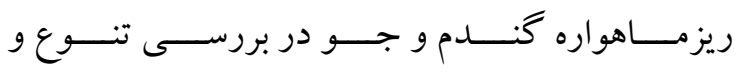
ساختار زنتيكى و نيـز تعيسين روابـط بـين زنوتيـبِهـا در

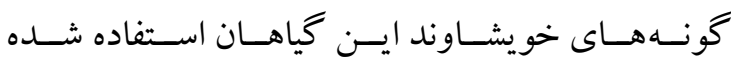
(Sourdille et al., 2001; Holton et al., 2002;

Sharma et al., 2002; Zhang 2006; Castillo et al.,

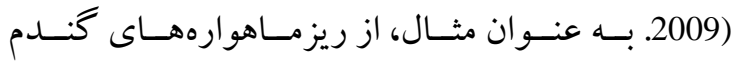

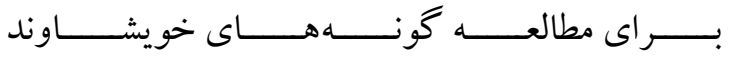

T. durum ،(Fahima et al., 1998) T. dicoccoides Ae. tauschii ،T. timopheevii ،(Korzun et al., 1999) Ae. ‘(Pestsova et al., 2000; Sourdille et al., 2001) (Sourdille et Ae. searsii ‘Ae. Longissima sspeltoides .S. cereale ،al., 2001; Adonina et al., 2005) (Röder et al., H. vulgare ‘Triticosecale (triticale) 
"نشريه علوم زراعى ايران"، جلد بيست و دوم، شماره Y، تابستان 99سا

جدول ا- جنس، گونه و تر كيب زنومى زنوتيبهاى Triticum و Aegilops مورد مطالعه

Table 1. Genera, species and genomic composition of Triticum and Aegilops genotypes

\begin{tabular}{|c|c|c|c|c|c|c|c|}
\hline $\begin{array}{c}\text { Species } \\
\text { Specis }\end{array}$ & زُزوم & $\begin{array}{c}\text { كد زنو تيتب } \\
\text { Access. code }\end{array}$ & $\begin{array}{l}\text { محل جمع آورى } \\
\text { Location }\end{array}$ & $\begin{array}{c}\text { Species } \\
\text { Specis }\end{array}$ & زُزوم & $\begin{array}{c}\text { كد زنوتيب } \\
\text { Access. code }\end{array}$ & $\begin{array}{l}\text { محل جمع آورى } \\
\text { Location }\end{array}$ \\
\hline Ae. ambellulata & $\mathrm{U}$ & KC-50032 & - & Ae. columnaris & UM & TN-01-0314 & West Azer.- Urmia \\
\hline Ae. ambellulata & $\mathrm{U}$ & $\mathrm{TN}-01-726$ & Fars-Fars & Ae. columnaris & UM & TN-01-0860 & West Azer.- Urmia \\
\hline Ae.ambellulata & $\mathrm{U}$ & TN-01-785 & Ilam-Darrehshahr & Ae. columnaris & UM & TN-01-0864 & - \\
\hline Ae. ambellulata & $\mathrm{U}$ & KC-50053 & - & Ae. columnaris & UM & TN-01-0289 & Zanjan-Takestan \\
\hline Ae. ambellulata & $\mathrm{U}$ & TN-01-725 & Fars-Fars & Ae. speltoides & S & KC-50043 & Kurdistan-Marivan \\
\hline Ae. triuncialis & $\mathrm{UC}$ & KC-50018 & - & Ae. speltoides & $S$ & KC-50049 & - \\
\hline Ae. triuncialis & $\mathrm{UC}$ & KC-50016 & - & Ae. speltoides & S & KC-50051 & - \\
\hline Ae. triuncialis & $\mathrm{UC}$ & KC-50004 & Markazi-Delijan & Ae. speltoides & S & KC-50045 & Kurdistan-Bane \\
\hline Ae. triuncialis & UC & KC-50012 & Tehran-Damavand & Ae. speltoides & $\mathrm{S}$ & KC-50047 & Kurdistan-Bane \\
\hline Ae. triuncialis & UC & KC-50010 & Tehran-Tehran & T. araraticum & AG & KC-55059 & West Azer.-Sardasht \\
\hline Ae. crassa & DM & KC-50119 & Khorasan- Bojnurd & T. araraticum & $\mathrm{AG}$ & KC-55061 & - \\
\hline Ae. crassa & DM & TN-0744 & - & T. araraticum & AG & KC-55058 & West Azer.-Sardasht \\
\hline Ae. crassa & $\mathrm{DM}$ & TN-0730 & - & T. araraticum & AG & KC-55060 & - \\
\hline Ae. crassa & DM & TN-50092 & - & T. boeoticum & A & KC-55035 & - \\
\hline Ae. crassa & $\mathrm{DM}$ & TN-0723 & Fars-Fars & T. boeoticum & A & KC-55033 & Kurdistan-Bane \\
\hline Ae. tauschii & $\mathrm{D}$ & TN-621 & Khorasan- Bojnurd & T. boeoticum & A & KC-55034 & Kurdistan-Bane \\
\hline Ae. tauschii & $\mathrm{D}$ & TN-304 & West Azer.- Urmia & T. boeoticum & A & KC-55036 & - \\
\hline Ae. tauschii & $\mathrm{D}$ & TN-697 & - & T. urartu & A & KC-55047 & - \\
\hline Ae. tauschii & $\mathrm{D}$ & TN-308 & West Azer.- Urmia & T. urartu & A & KC-55043 & West Azer.-Sardasht \\
\hline Ae. tauschii & $\mathrm{D}$ & TN-50006 & - & T. urartu & A & KC-55045 & Ilam-Ilam \\
\hline
\end{tabular}

دماى VY درجه سانتى گراد به مدت . r ثانيه و در نهايت يكك جر خه بسط نهايى در دماى VY درجسه سـانتى گر اد

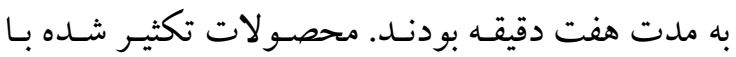

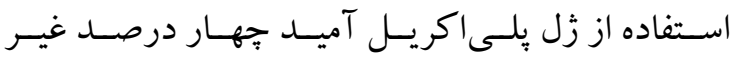

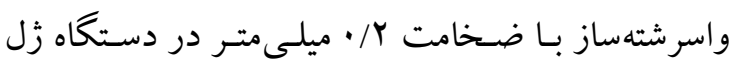

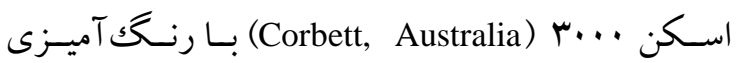
اتيديومبروومايد تفكيكك شدند. براى تعيسين انسدازه نسـبى

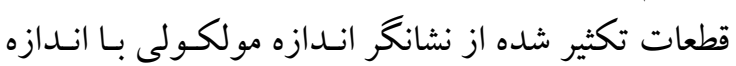
قطعات . . . 1- ·ه جفت بازى در سه قسمت زل استفاده كرديل. ميز ان انتقال يـذيرى نشـانكر هاى ريزمـاهو اره جـو در خويشاوندان كندم به صورت نشانكرهايى با تكثير موفق

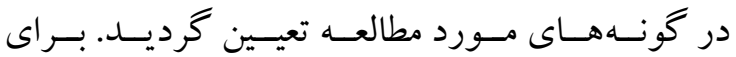
نشانگرهاى جندشكل، تعداد آلل (N)، تنوع زنسى (H) ميززان اطلاعـات جنـــ شـكلى (PIC)، تعـداد آلل مـؤثر (Ne)، تعداد آل خصوصى، شـاخص اطلاعـات شـانون

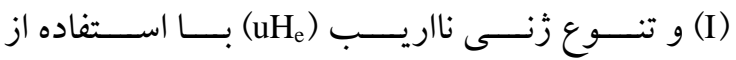

GBM (Li et al., 2003) و (Ramsay et al., 2000) استفاده شد كـه جايخـاه كرومـوزومى \1 نشـانكر روى

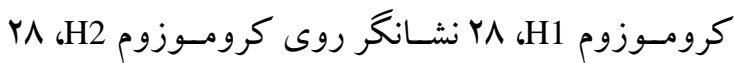

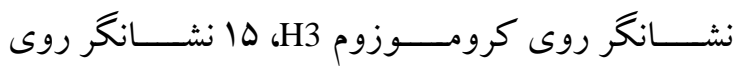

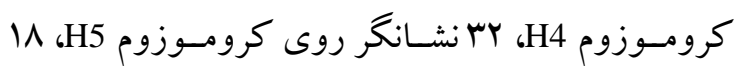

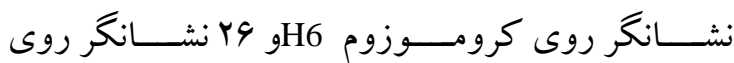
كروموزوم H7 قرار داشتند.

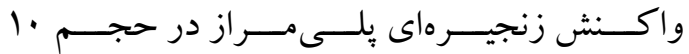

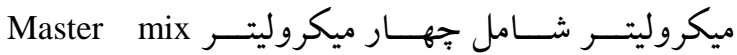
يكك ميكروليتر از (https://ampliqon.com/en/products) هـــر آغـــاز گر، دو ميكروليتــر DNA زنـــومى و ســهـ ميكروليتر آب دى يونيزه بود. جر خههاى حرارتى شـامل

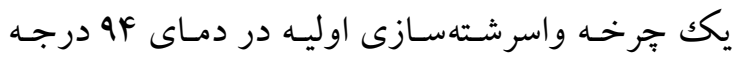

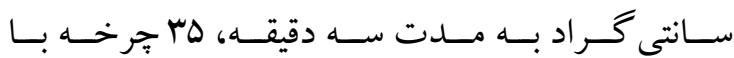

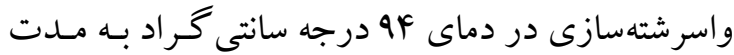

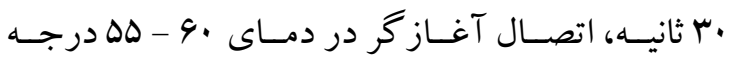
سانتى گراد (بسته به آغاز گر) به مدت ·م ثانيه و بسط در 
با شاخصهاى تكثير غير اختصاصى، نوارهـاى ضعيف،

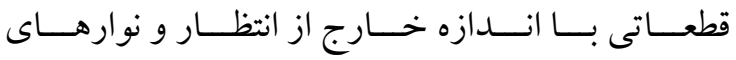
كشيده (Stutter) ارائه شده توسط كاستيلو و همكاران بودند، از تجزيه و تحليل حذف (Castillo et al., 2008) شدند. بر اساس اين جهار شاخص، از هه جفت آغاز

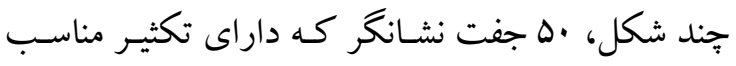

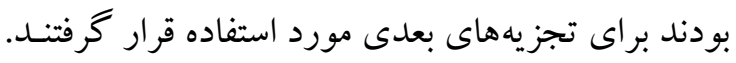

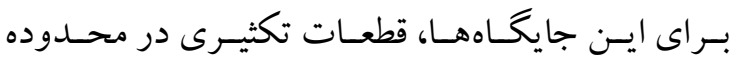

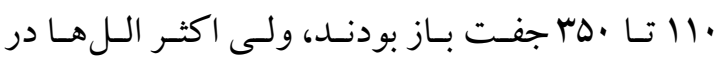

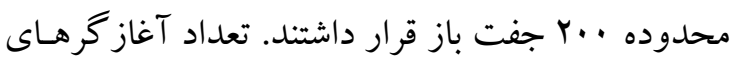

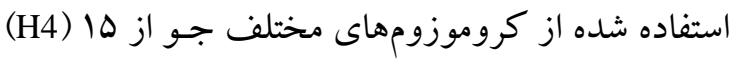

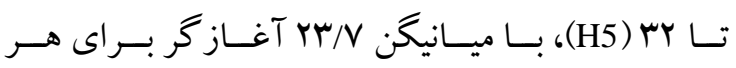

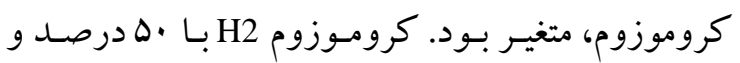
كروموزوم H3 با OQ در درصد، به ترتيب بيشترينو كمترين

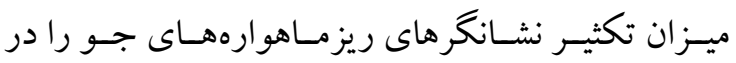
جسنس هـاى Aegilpos و Triticum داشـتند. بيشـترين و كمترين ميز ان نشانگر هاى جند شكل به ترتيب متعلق بـهـ

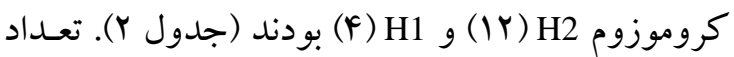

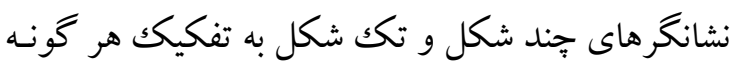
در جدول ب ارائه شده است. بيشترين و كمتـرين ميـزان

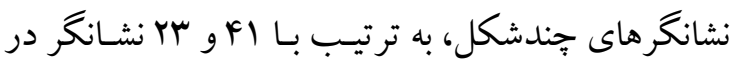
Thartu و Ae. columnaris

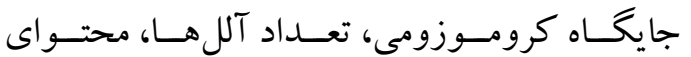

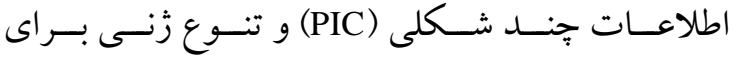

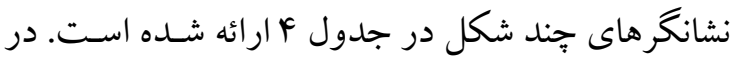

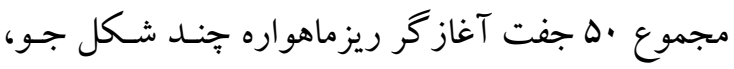

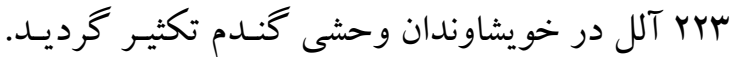

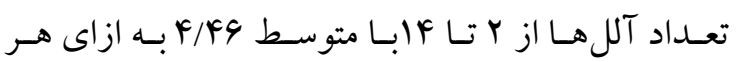

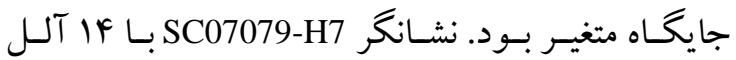

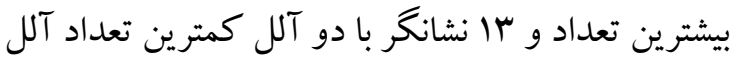

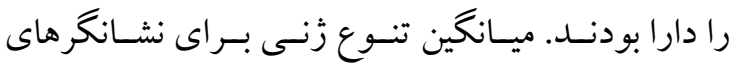

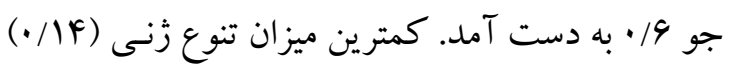

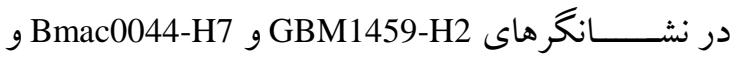

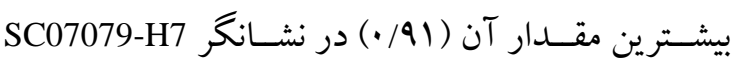

(Liu and Muse, PowerMarker 3.25 نـرم|فزارهـاى (Peakall and Smouse, 2012) GenAlEx6.5 2005)

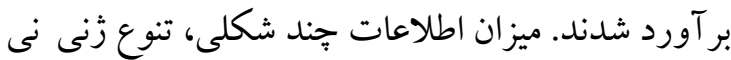
و شاخص شانون به ترتيب بـا اسـتفاده از رابطههاى زيـر

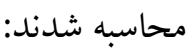
(Botstein et al., 1980) $\quad \mathrm{PIC}=1-\sum \mathrm{p}_{\mathrm{i}}^{2}-\sum 2 \mathrm{p}_{\mathrm{i}}^{2} \mathrm{p}_{\mathrm{j}}^{2}(\mathrm{l}$ (رابط (Nei, 1973) $\mathrm{He}=1-\sum p_{i}^{2} \quad($ رابطه $)$ $\left(\right.$ Nei, 1978) $\mathrm{uHe}=2 \mathrm{n}\left(1-\sum \mathrm{p}_{\mathrm{i}}^{2}\right) /(2 \mathrm{n}-1) \quad($ رابطه $)$ (Magurran 2004) $I=-1 * \sum\left(p_{i} * \ln p_{i}\right) \quad($ رابطه در اين رابطهها، و زام در يكك جايگاه ريزماهواره مىباشند.

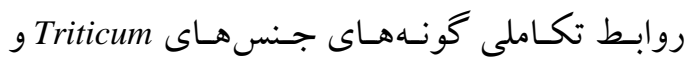
بegilops

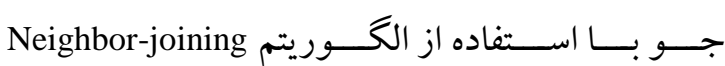

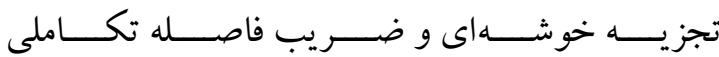
MEGA V.5/05 با استفاده از نـرمافزار Juckes Cantor انجام و براى تعيين تعداد خوشـهـ (Tamura et al., 2011) مطلوب از روش Bootstrap استفاده شد. علاوه بـر ايسن، تجزيسه بـهـ بردارهـاى اصسلى (PCoA) بـه عنسوان روش

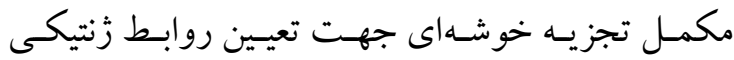

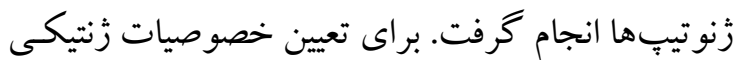

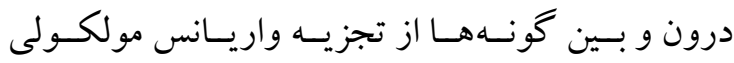

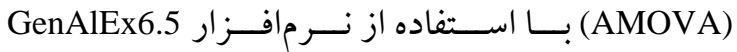
(Peakall and Smouse, 2012)

\section{نتايج و بحث}

نتايج نشان داد كه از 190 جفت آغاز كر ريزماهو اره

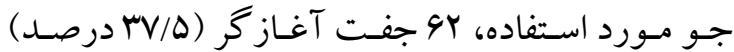

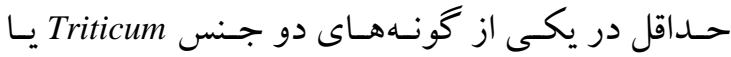

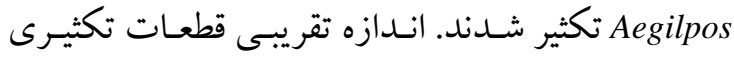

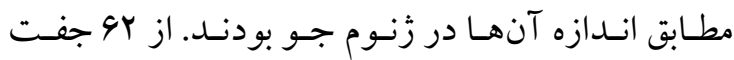

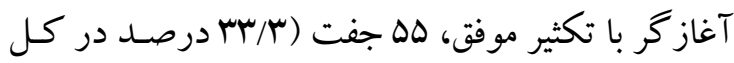

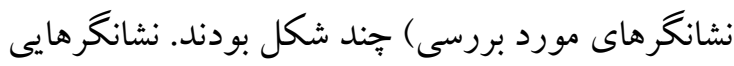


"نشريه علوم زراعى ايران"، جلد بيست و دوم، شماره ب، تابستان وج؟ا

جدول r- انتقال يذيرى نشانگرهاى ريزماهواره جو در جنس هاى Aegilops وبر اساس كل نشانگرهاى ريزماهواره ارزيابى شده، نشانگرهاى تكثير شده و نشانگ هاى جندشكل

Table 2. Transferability of barley SSR markers in Triticum and Aegilops species based on number of total SSR markers, amplified SSR markers and polymorphic SSR markers

\begin{tabular}{|c|c|c|c|c|c|c|c|c|}
\hline & \multicolumn{8}{|c|}{$\begin{array}{l}\text { كروموزومهاى جو } \\
\text { Barley chromosomes }\end{array}$} \\
\hline & $\mathrm{H} 1$ & $\mathrm{H} 2$ & $\mathrm{H} 3$ & $\mathrm{H} 4$ & H5 & $\mathrm{H} 6$ & $\mathrm{H} 7$ & $\begin{array}{c}5 \\
\text { Total } \\
\end{array}$ \\
\hline كل نشانخرهاى ريزماهو اره ارزيابى شده & 18 & 28 & 28 & 15 & 32 & 18 & 26 & 165 \\
\hline Amplified SSR markers نشانخرهاى ريزماهواره تكثير شده & $\begin{array}{c}5 \\
(27.7 \%)\end{array}$ & $\begin{array}{l}14 \\
(50.0 \%)\end{array}$ & $\begin{array}{c}7 \\
(25.0 \%)\end{array}$ & $\begin{array}{c}7 \\
(46.6 \%)\end{array}$ & $\begin{array}{l}13 \\
(40.6 \%)\end{array}$ & $\begin{array}{c}8 \\
(44.4 \%)\end{array}$ & $\begin{array}{c}8 \\
(30.7 \%)\end{array}$ & $\begin{array}{l}62 \\
(37.7 \%)\end{array}$ \\
\hline Polymorphic SSR markers نشانخرهاى ريزماهو اره جند شكل & $\begin{array}{c}4 \\
(22.2 \%)\end{array}$ & $\begin{array}{l}12 \\
(42.8 \%)\end{array}$ & $\begin{array}{c}6 \\
(21.4 \%)\end{array}$ & $\begin{array}{c}7 \\
(46.6 \%)\end{array}$ & $\begin{array}{l}12 \\
(37.5 \%)\end{array}$ & $\begin{array}{c}7 \\
(38.8 \%)\end{array}$ & $\begin{array}{c}7 \\
(26.9 \%)\end{array}$ & $\begin{array}{l}55 \\
(33.3 \%)\end{array}$ \\
\hline
\end{tabular}

جدول س- جند شكلى و تكك شكلى نشانكرهاى ريزماهو اره جو در جنس هاى Ariticum و Aegilops

Tabel 3. Polymorphic and monomorphic barley SSR markers in Triticum and Aegilops species

\begin{tabular}{|c|c|c|c|}
\hline 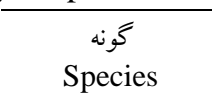 & $\begin{array}{c}\text { كل نشانگر ها } \\
\text { Total markers }\end{array}$ & $\begin{array}{c}\text { نشانخر هاى تك شكل } \\
\text { Monomorph markers }\end{array}$ & $\begin{array}{c}\text { نشانكرهاى جند شكل } \\
\text { Polymorph markers }\end{array}$ \\
\hline Ae. ambellulata & 50 & $9(18 \%)$ & $41(82 \%)$ \\
\hline Ae. ttiuncialis & 50 & $15(30 \%)$ & $35(70 \%)$ \\
\hline Ae. crassa & 50 & $21(42 \%)$ & $29(58 \%)$ \\
\hline Ae. tauschii & 50 & $23(46 \%)$ & $27(54 \%)$ \\
\hline Ae. columnaris & 50 & $8(16 \%)$ & $42(84 \%)$ \\
\hline Ae. speltoides & 50 & $20(40 \%)$ & $30(60 \%)$ \\
\hline T. araraticum & 50 & $22(44 \%)$ & $28(56 \%)$ \\
\hline T. boeoticum & 50 & $23(46 \%)$ & $27(54 \%)$ \\
\hline T. urartu & 50 & $27(54 \%)$ & $23(46 \%)$ \\
\hline
\end{tabular}




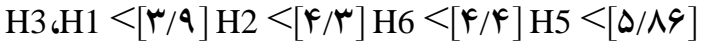

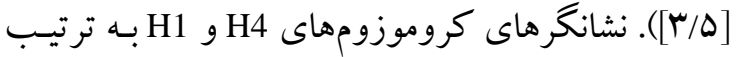

بيشترين و كمترين ميزان تنوع زنسى و PIC را دارا بودنـــ

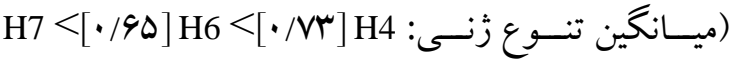

، $[\cdot / \Delta \mathrm{Y}] \mathrm{H} 2 \quad{ }_{6} \mathrm{H} 1<[\cdot / 9] \mathrm{H} 5<[\cdot / 9 \mathrm{r}] \mathrm{H} 3<[\cdot / 9 \mathrm{Y}]$

H3 $<[\cdot / 9] \mathrm{H} 7$ [H6

.$([\cdot / \mathcal{Q} \varphi] \mathrm{H} 1<[\cdot / \mathcal{F A}] \mathrm{H} 2<[\cdot / \Delta \Delta] \mathrm{H} 5<[\cdot / \Delta \mathrm{V}]$

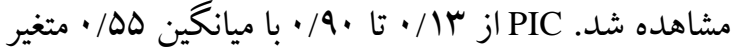
بود كـه بيشـترين مقـدار آن بـه نشـانكر SC07079-H7 و . كمتــرين مقــدار آن بـه نشـانكرهاى GBM1459-2H و Bmac0044-H7 تعلـق داشـت. بيشـترين ميـانگين تعـداد

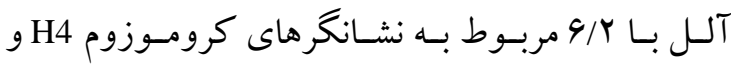
كمترين آن با ه/س مربوط به نشانكر هاى كروموزومهاى

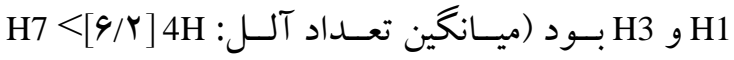

جدول F- آغاز گرهاى ريزماهواره، جايگًاه كروموزومى (Ch)، تعداد آلل (Na)، محتواى اطلاعات جند شكلى (PIC) و تنوع زنى (Hegilops ور جنس هاى Triticum

Table 4. Microsatellite primers, Chromosome location $(\mathrm{Ch})$, Alleles number $\left(\mathrm{N}_{\mathrm{a}}\right)$, Polymorphic information content (PIC) and gene variation $\left(\mathrm{H}_{\mathrm{e}}\right)$ in Triticum and Aegilops species

\begin{tabular}{|c|c|c|c|c|c|c|c|c|c|}
\hline $\begin{array}{c}\text { آغاز گرهاى ريزماهواره } \\
\text { Microsatellite primers }\end{array}$ & $\mathrm{Ch}$ & $\mathrm{N}_{\mathrm{a}}$ & PIC & $\mathrm{H}_{\mathrm{e}}$ & $\begin{array}{c}\text { آغاز كرهاى ريزماهواره } \\
\text { Microsatellite primers }\end{array}$ & $\mathrm{Ch}$ & $\mathrm{N}_{\mathrm{a}}$ & PIC & $\mathrm{H}_{\mathrm{e}}$ \\
\hline GBM1092 & H1 & 2 & 0.19 & 0.22 & GBM1176 & $\mathrm{H} 5$ & 3 & 0.59 & 0.66 \\
\hline GBM1234 & $\mathrm{H} 1$ & 7 & 0.83 & 0.85 & GBM1405 & H5 & 5 & 0.67 & 0.73 \\
\hline GBM1480 & H1 & 3 & 0.50 & 0.58 & $G B M 1426$ & H5 & 5 & 0.66 & 0.72 \\
\hline SCSSR 04163 & $\mathrm{H} 1$ & 2 & 0.34 & 0.44 & GBM1470 & H5 & 2 & 0.37 & 0.50 \\
\hline ميانغين كروموزوم H1 & & \multirow{2}{*}{3.5} & \multirow{2}{*}{0.46} & \multirow{2}{*}{0.52} & SCSSR02306 & H5 & 5 & 0.61 & 0.66 \\
\hline Mean H1 chromosome & & & & & SCSSR02503 & H5 & 2 & 0.27 & 0.32 \\
\hline Bmac0576 & $\mathrm{H} 2$ & 3 & 0.36 & 0.40 & SCSSR07106 & H5 & 9 & 0.85 & 0.86 \\
\hline GBM1187 & $\mathrm{H} 2$ & 7 & 0.81 & 0.84 & SCSSR15334 & H5 & 4 & 0.51 & 0.56 \\
\hline GBM1251 & $\mathrm{H} 2$ & 2 & 0.16 & 0.18 & SCSSR16991 & H5 & 7 & 0.70 & 0.74 \\
\hline GBM1309 & $\mathrm{H} 2$ & 6 & 0.58 & 0.63 & SCSSR18076 & H5 & 2 & 0.25 & 0.29 \\
\hline GBM1366 & $\mathrm{H} 2$ & 3 & 0.57 & 0.65 & ميانگين كروموزوم H5 & & \multirow{2}{*}{4.4} & \multirow{2}{*}{0.55} & \multirow{2}{*}{0.6} \\
\hline GBM1408 & $\mathrm{H} 2$ & 2 & 0.29 & 0.35 & Mean H5 chromosome & & & & \\
\hline GBM1440 & $\mathrm{H} 2$ & 6 & 0.75 & 0.77 & Bmag0210 & H6 & 4 & 0.53 & 0.57 \\
\hline GBM1446 & $\mathrm{H} 2$ & 6 & 0.72 & 0.76 & Bmag0500 & H6 & 5 & 0.71 & 0.75 \\
\hline GBM1459 & $\mathrm{H} 2$ & 2 & 0.13 & 0.14 & Bmag0867 & H6 & 4 & 0.68 & 0.73 \\
\hline SCSSR00334 & $\mathrm{H} 2$ & 5 & 0.68 & 0.72 & GBM1087 & H6 & 3 & 0.46 & 0.55 \\
\hline SCSSR03381 & $\mathrm{H} 2$ & 2 & 0.22 & 0.25 & GBM1400 & $\mathrm{H} 6$ & 4 & 0.56 & 0.61 \\
\hline SCSSR08447 & $\mathrm{H} 2$ & 3 & 0.51 & 0.6 & SCSSR02093 & H6 & 3 & 0.45 & 0.50 \\
\hline H2 ميانخين كروموزوم & & \multirow{2}{*}{3.9} & \multirow{2}{*}{0.48} & \multirow{2}{*}{0.52} & SCSSR05599 & H6 & 7 & 0.80 & 0.82 \\
\hline Mean $\mathrm{H} 2$ chromosome & & & & & H6 ميانكين كروموزوم H6 & & \multirow{2}{*}{4.3} & \multirow{2}{*}{0.6} & \multirow{2}{*}{0.65} \\
\hline GBM1118 & $\mathrm{H} 3$ & 3 & 0.55 & 0.62 & Mean H6 chromosome & & & & \\
\hline$G B M 1163$ & $\mathrm{H} 3$ & 2 & 0.34 & 0.44 & Bmac0044 & $\mathrm{H} 7$ & 2 & 0.13 & 0.14 \\
\hline GBM1300 & $\mathrm{H} 3$ & 2 & 0.32 & 0.40 & Bmac0064 & $\mathrm{H} 7$ & 4 & 0.57 & 0.62 \\
\hline GBM1450 & $\mathrm{H} 3$ & 5 & 0.74 & 0.77 & Bmac0224 & $\mathrm{H} 7$ & 5 & 0.69 & 0.74 \\
\hline SCSSR 25691 & $\mathrm{H} 3$ & 4 & 0.69 & 0.74 & GBM1102 & $\mathrm{H} 7$ & 2 & 0.36 & 0.47 \\
\hline ميانكين كروموزوم H3 & & \multirow{2}{*}{3.5} & \multirow{2}{*}{0.57} & \multirow{2}{*}{0.63} & GBM1432 & $\mathrm{H} 7$ & 6 & 0.76 & 0.79 \\
\hline Mean H3 chromosome & & & & & SCSSR07970 & $\mathrm{H} 7$ & 14 & 0.90 & 0.91 \\
\hline GBM1364 & $\mathrm{H} 4$ & 6 & 0.64 & 0.68 & SCSSR15864 & $\mathrm{H} 7$ & 8 & 0.81 & 0.83 \\
\hline GBM1422 & $\mathrm{H} 4$ & 5 & 0.57 & 0.62 & H7 ميانكين كروموزوم & & \multirow[b]{2}{*}{5.86} & \multirow[b]{2}{*}{0.6} & \multirow[b]{2}{*}{0.64} \\
\hline GBM1501 & $\mathrm{H} 4$ & 6 & 0.78 & 0.81 & Mean H7 chromosome & & & & \\
\hline SCSSR 14079 & $\mathrm{H} 4$ & 9 & 0.82 & 0.85 & ميانكين كل & & \multirow{2}{*}{4.46} & \multirow{2}{*}{0.55} & \multirow{2}{*}{0.6} \\
\hline SCSSR 18005 & $\mathrm{H} 4$ & 5 & 0.61 & 0.67 & Total mean & & & & \\
\hline $\begin{array}{c}\text { H4 ميانكين كروموزوم } \\
\text { Mean H4 chromosome }\end{array}$ & & 6.2 & 0.68 & 0.73 & & & & & \\
\hline
\end{tabular}

الكوريتم Neighbor-joining تجزيه خوشـهاى و ضـريب فاصـله تكـاملى Juckes Cantor مـورد ارزيسابى قــرار
روابط تكاملى زنوتيبـهاى مـورد مطالعهه بـر اسـاس

دادههـاى نشـانكر هاى ريزمـاهواره جــو بــا اسـتفاده از 
دو زَنوتي ديخـر Ae. columnaris Zhuk. (UUMM)

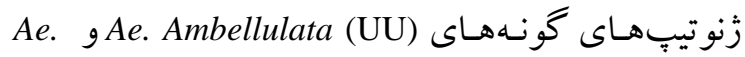
triuncialis L. (UUCC)

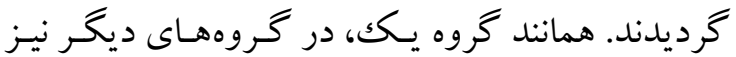
شباهت زنومى بين اعضاى گروه ديده شد و افراد داراى زنوم مشابه در گروههاى يكسان قرار گرفتند. عـلاوه بـر تجزيه خوشهاى از PCoA نيز براى تعيين روابط تكـاملى كونهها استفاده شد. در PCoA، سه بـردار اصسلى اول بـه

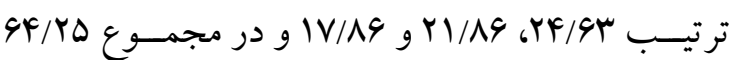
درصد از تغييرات مولكولى كل نشانكرهاى ريزمـاهواره

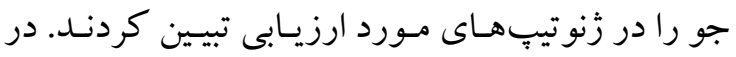

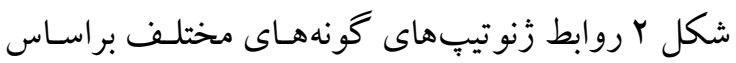
دو بردار اصلى اول نشان داده شده اسـت. در تجزيسه بـه

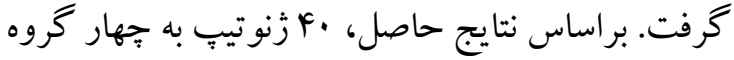
مختلف منتسب شدند كـه بـه مقـدار زيـادى بـا سـاختار زَنومى و روابط تكاملى آنها مطابقت داشت (شكل ().

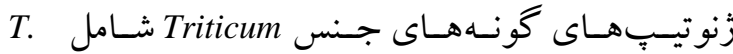
T. $T$. Urartu (AA) sararaticum (AAGG) boeoticum Boiss. (AA) همه زَنوتيٍٍ هاى متعلق بـه جـنس Triticum كـه در ايسن تحقيق وجود داشتند، در اين گحروه قـرار كرفتند. نكتـه مشتر كك ديكر اعضاى كروه يك داشتن زنوم A بود. دو

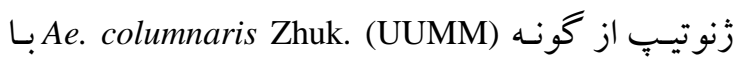

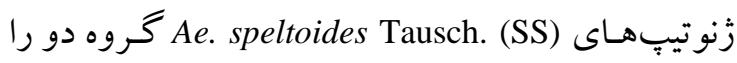
Ae. tauschii Coss. تشكيل دادند. زنوتيٍ هاى دو كونه Ae. crassa Boiss. (DDMM) بـه گرووه سوم و (DD)

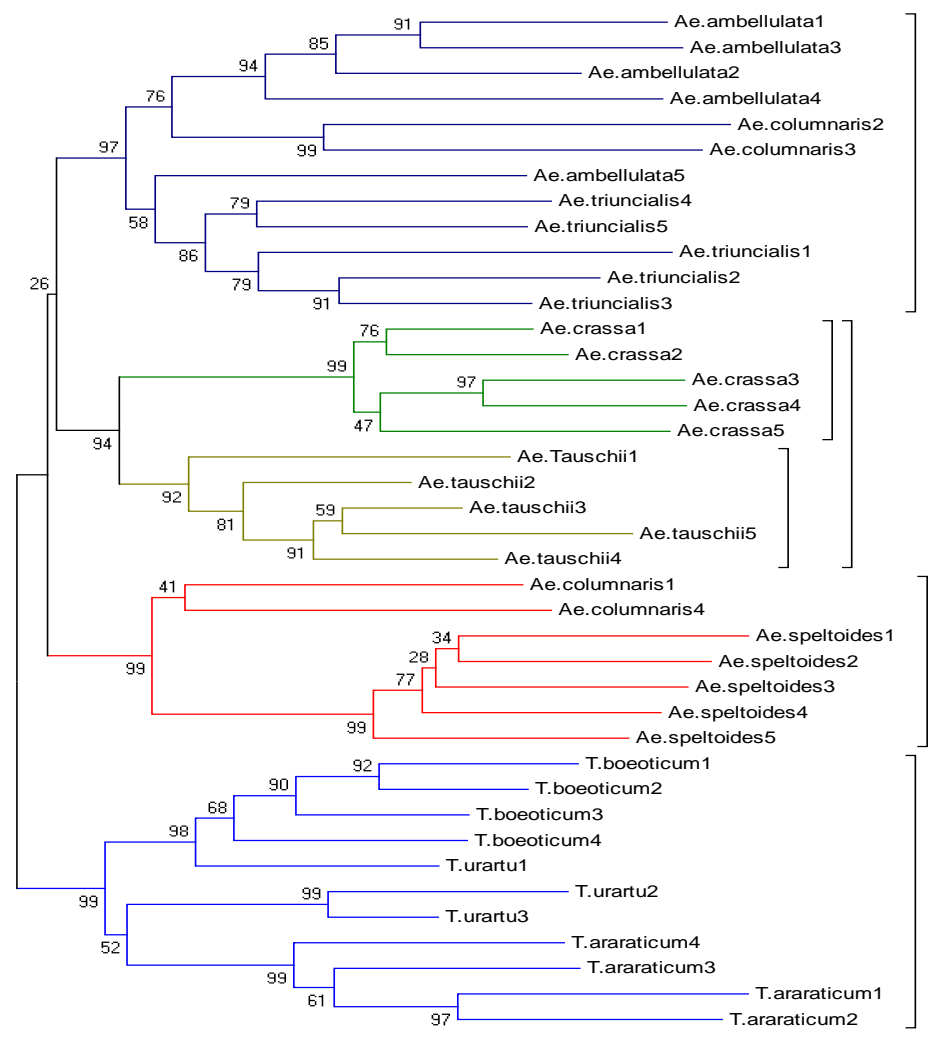

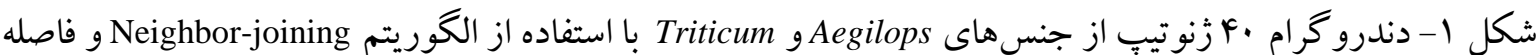
تكاملى Juckes Cantor بر اساس نشانكر هاى ريزماهواره جو

Fig. 1. Dendrogram of 40 accessions of Aegilops and Triticum using Neighbor-joining algorithm and Juckes Cantor distance coefficient based on barley SSR markers 
" انتقال يٍ يرى نشانگر هاى ريزماهو اره...، احمد احمدى لكى و همكاران،

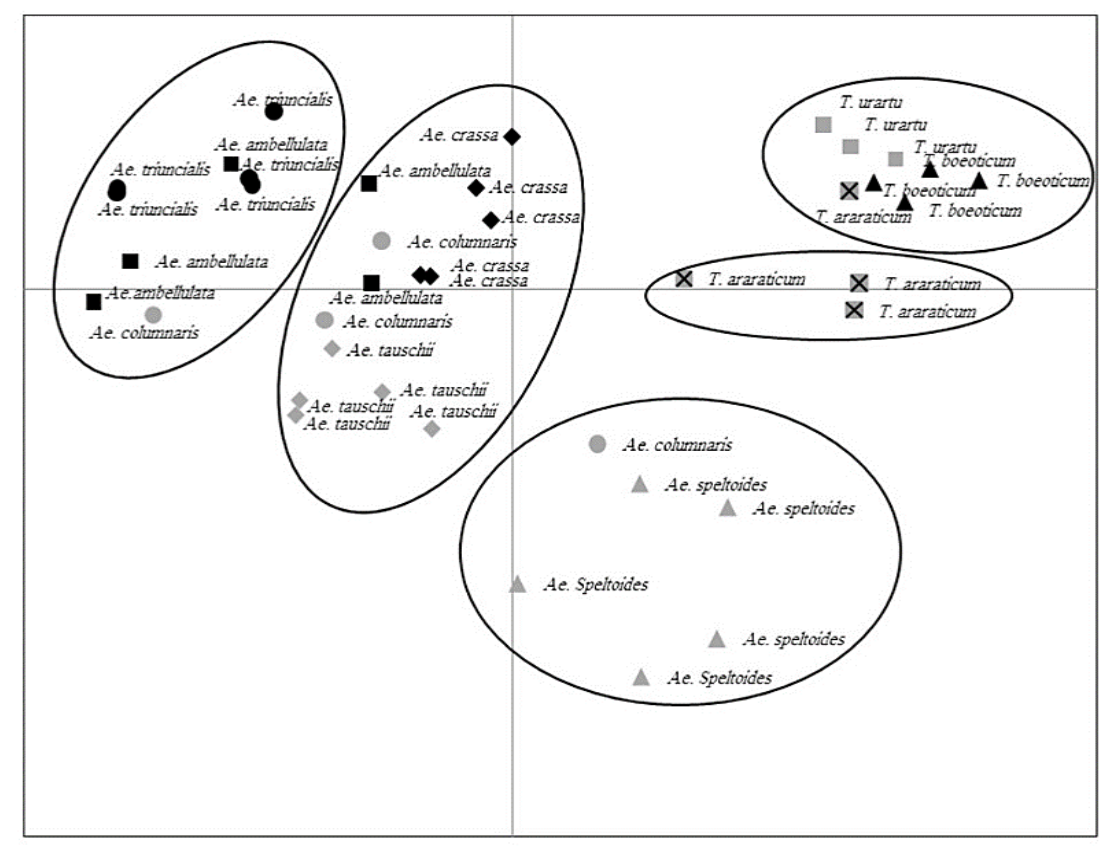

ని

PCo1

شكل Y- يُ اكنش زنو تيّهاى جنس هاى Aegilops و بر اساس دو بردار اول تجزيه به بردارهاى اصلى

Fig. 2. Plot of the first and second principal components according to barley SSR markers in Aegilops and

Triticum species

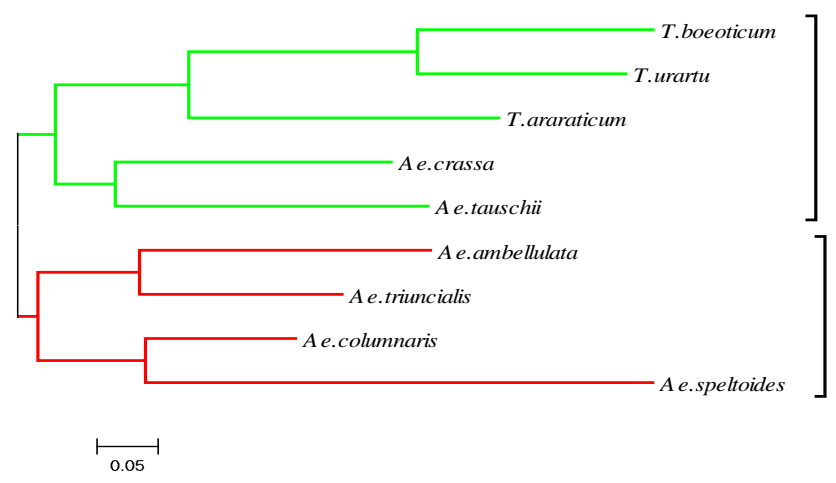

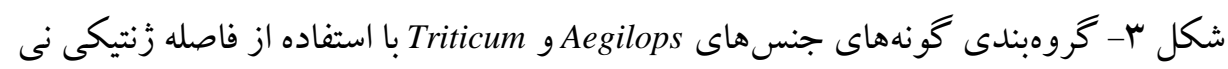

Fig. 3. Neighbor-joining dendrogram based on Nei's genetic distance in Aegilops and Triticum species

گونه جنس Triticum در يك گروه و سـاير گونسهـاى Aegilops

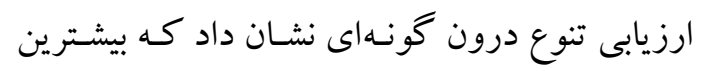

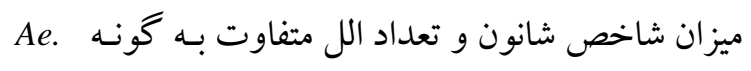

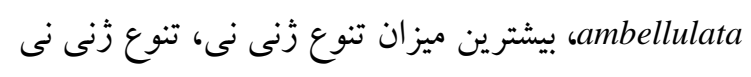

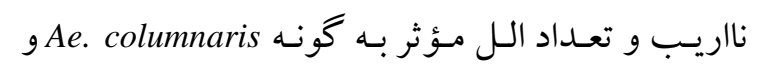

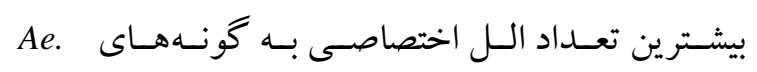

بردارهاى اصلى نيز افراد گونهها براساس شباهت زنومى

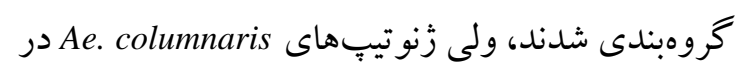

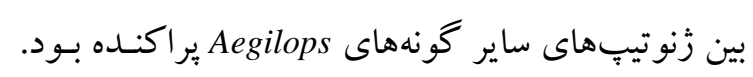

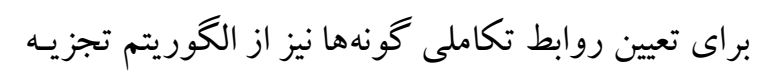
خوشهاى Neighbor-joining براساس فاصله زنتيكى نسى رونى (Nei, 1973)

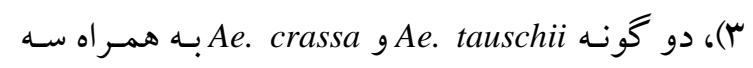


urartu مشـاهده شـد (جــدول ه). براسـاس AMOVA،

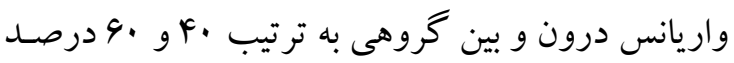

$$
\text { واريانس مولكولى كل را تبيين كردند. }
$$

speltoides مقدار اين بارامترها، به غير از تعداد اللل اختصاصسى كـه كمترين مقدار آن مربوط به Ae. columnaris بود، در . Tكين

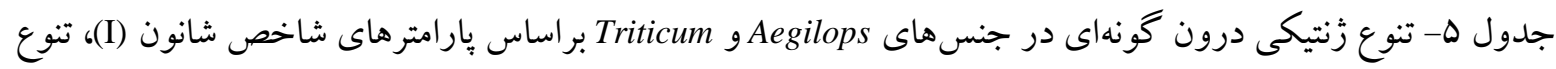

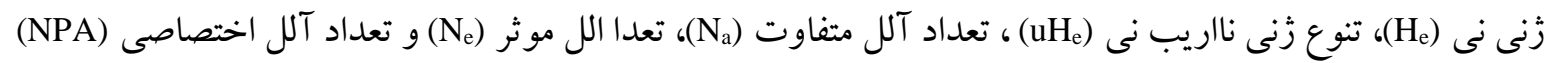

Table 5. Within group genetic diversity of species based on Shannon's index (I), Nei's gene diversity $\left(H_{e}\right)$, unbiased Nei's gene diversity $\left(\mathrm{uH}_{\mathrm{e}}\right)$, Number of different alleles $\left(\mathrm{N}_{\mathrm{a}}\right)$, Number of effective alleles $\left(\mathrm{N}_{\mathrm{e}}\right)$ and number of private alleles (NPA) in Aegilops and Triticum species

\begin{tabular}{|c|c|c|c|c|c|c|}
\hline $\begin{array}{c}\text { كونه } \\
\text { Species }\end{array}$ & I & $\mathrm{H}_{\mathrm{e}}$ & $\mathrm{uH}_{\mathrm{e}}$ & $\mathrm{N}_{\mathrm{a}}$ & $\mathrm{N}_{\mathrm{e}}$ & NPA \\
\hline Ae. ambellulata & $0.61(0.05)^{*}$ & $0.38(0.03)$ & $0.43(0.03)$ & $2.16(0.11)$ & $1.83(0.09)$ & $0.16(0.06)$ \\
\hline Ae. triuncialis & $0.05(0.05)$ & $0.32(0.04)$ & $0.35(0.04)$ & $1.92(0.11)$ & $1.67(0.09)$ & $0.14(0.06)$ \\
\hline Ae. crassa & $0.40(0.06)$ & $0.26(0.03)$ & $0.29(0.04)$ & $1.74(0.12)$ & $1.56(0.07)$ & $0.10(0.05)$ \\
\hline Ae. tauschii & $0.38(0.05)$ & $0.24(0.03)$ & $0.27(0.04)$ & $1.72(0.10)$ & $1.49(0.08)$ & $0.10(0.04)$ \\
\hline Ae. columnaris & $0.59(0.05)$ & $0.39(0.03)$ & $0.45(0.04)$ & $2.04(0.10)$ & $1.85(0.10)$ & $0.04(0.03)$ \\
\hline Ae. speltoides & $0.43(0.06)$ & $0.28(0.03)$ & $0.31(0.04)$ & $1.80(0.11)$ & $1.59(0.09)$ & $0.16(0.05)$ \\
\hline T. araraticum & $0.38(0.05)$ & $0.25(0.03)$ & $0.29(0.04)$ & $1.70(0.10)$ & $1.50(0.08)$ & $0.14(0.06)$ \\
\hline T. boeoticum & $0.34(0.05)$ & $0.23(0.03)$ & $0.26(0.04)$ & $1.60(0.09)$ & $1.44(0.07)$ & $0.08(0.04)$ \\
\hline T. urartu & $0.30(0.05)$ & $0.20(0.03)$ & $0.24(0.04)$ & $1.50(0.09)$ & $1.40(0.08)$ & $0.06(0.03)$ \\
\hline
\end{tabular}

*The digits within parenthesis indicate standard errors of the parameters

كو جـك دار داى مقـدار DNA تكــرارى بيشـترى هسـتند (Ahn et al., 1993; Kurata et al., 1994) مقايسـهاى نقشـهــاى زنتيكى ذرت و بـرنج كـه حسدود

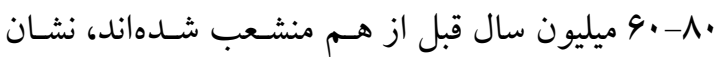
دهنده قطعات زنومى همخط بزرگك با محتوى و آرايش زنى حفاظت شده بين اين دو كونه است. وجود محتوى

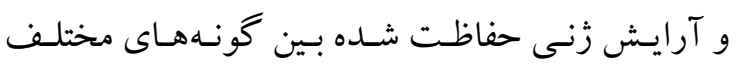

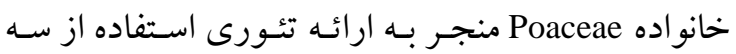
زنسوم كليـدى ذرت، جـو و بــرنج بـا زنــومهـاى نسـبتاً

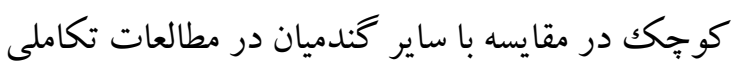
ساير كونهها گرديد (Bennetzen and Freeling, 1997). روابط تكاملى نزديكك بين كندم و جو در مقايسه بـا ساير اعضاى زراعى خانو اده Poaceae و حفاظت شدگى وسيع محتوى و آرايش زنى بين ايسن كونـه باعـث شـده است كه جو به علت دييلوييد بـودن، تعـداد كرومـوزوم

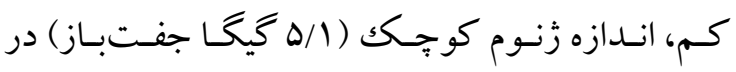

تهيسه اولـين نقشـه زنتيكـى سـور گوم بـا اسـتفاده از كاوشخرهاى DNA ذرت نشان داد كـه محتـواى زنـى و تعداد زنها در اين دو گونسه خويشـاوند بـه مقـدار زيـاد حفاظـت شــده اسـت و هــم خطـى بــالايى بـين اعظـم قسـمتهـاى زنـوم آنهـا مشـاهده كرديسـد. الكوهـاى دور گ گيرى توالىهـاى DNA ذرت و سـور گوم نشـان داد كه ايسن دو زنسوم بسـيار مشـابه هسـتند. بـا ايسن حـال توالى هاى موجود در DNA تكـرارى ذرت در برخسى از

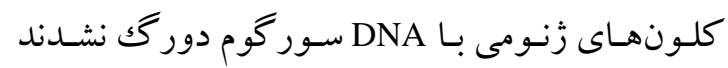

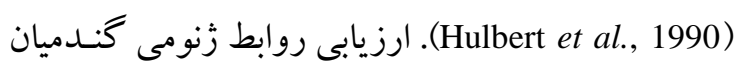
مختلف بر اساس نشانكرهاى مبتنى بر نـواحى زنسومى بـا

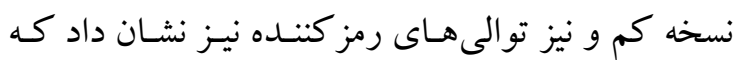

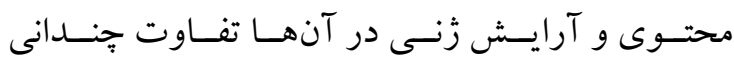

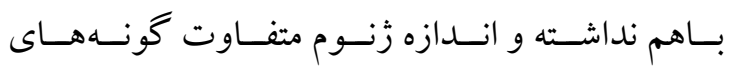
مختلف ناشى از تفاوت در ميـزان DNA تكـرارى آنهـا

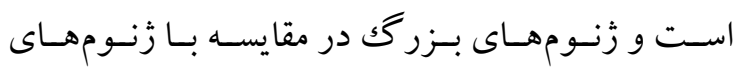


در ينج رقم گندم، ينج رقـم جـو، دو رقـم يـولاف و دو

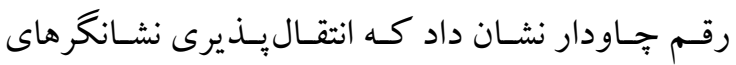

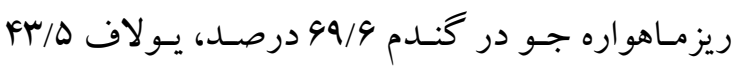

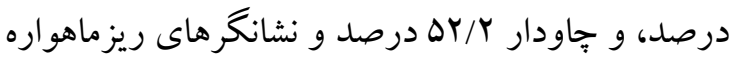

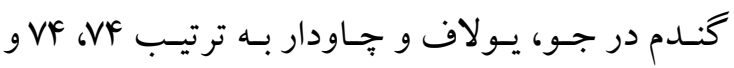

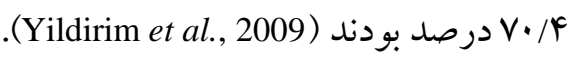
تجزيه خوشهاى بـا استفاده از دادههـاى نشـانكرهاى

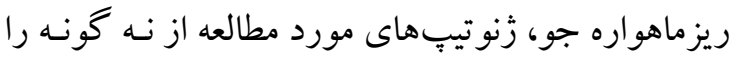

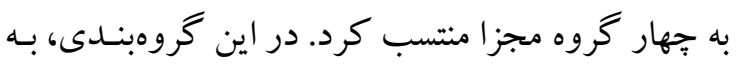

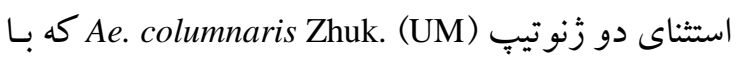

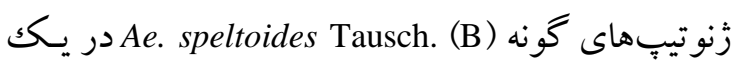

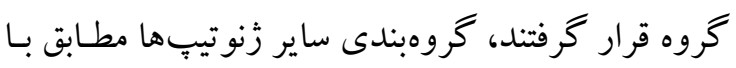

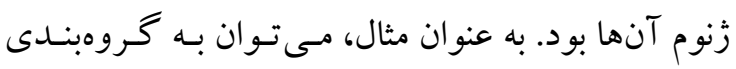

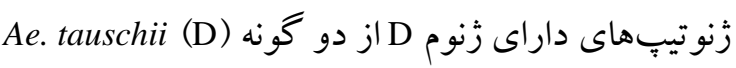
Coss. بـ و هـا هـم اشـاره كرد. Ae. crassa Boiss. (

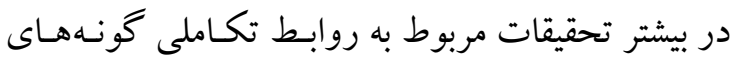

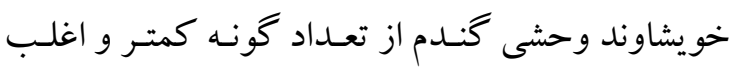

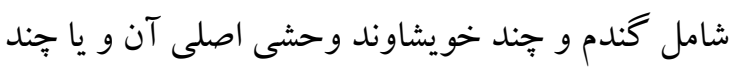

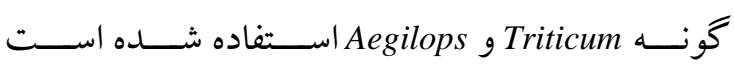
.(Petersen and Seberg, 2005; Mason-Gamer, 2005) در آزمــايش حاضــر، روابـط تكــاملى و تنــوع درون

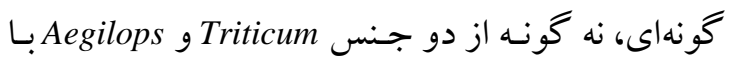

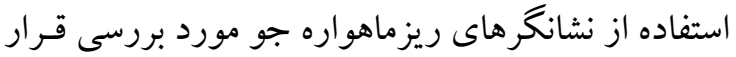

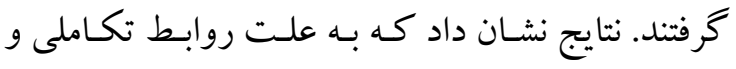
شباهت هاى زنومى نزديك كندم وخو يشاوندان وحشى

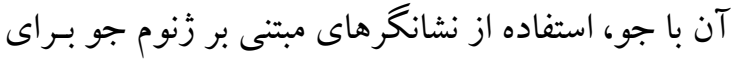

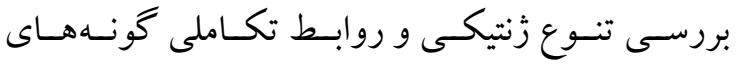
جنس هاى Triticum و Aegilops امكانيذير است.

\section{سياسگز ارى}

از قطـب علمسى اصـلاح مولكـولى غـلات دانشـكده

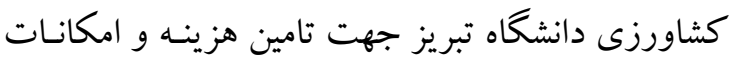
لازم براى انجام اين تحقيق سباسگز ارى مى شود.
مقايسه با گندم (V كيخا جفت باز) و دارا بودن صفاتى

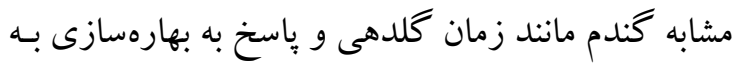

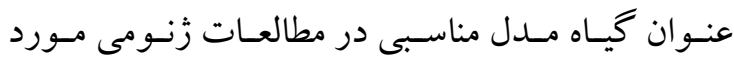

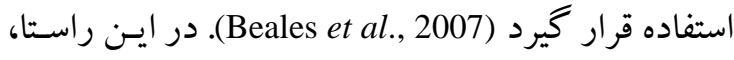

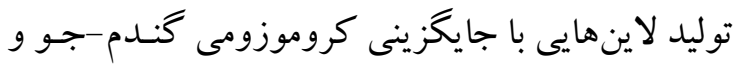

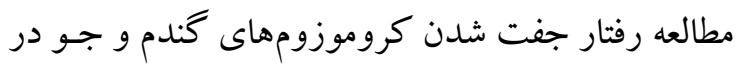

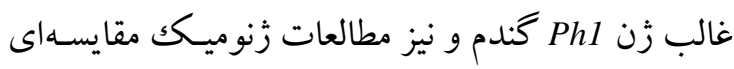

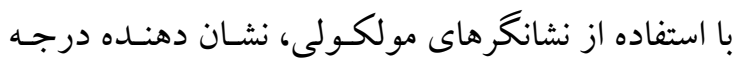

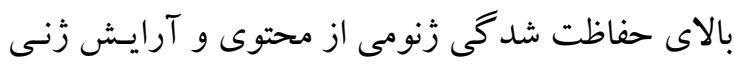

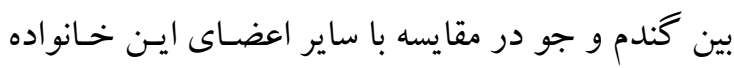

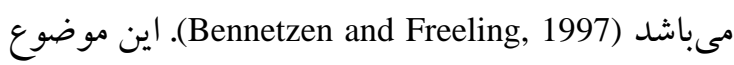
باعث شده است كه در تحقيقات مختلف از نشانكرهاى

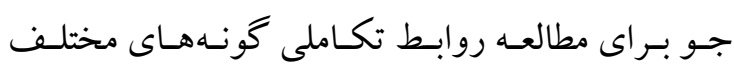
خانو اده گر امينه استفاده شود.

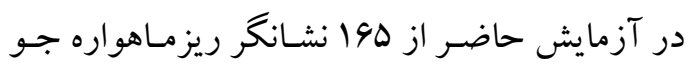

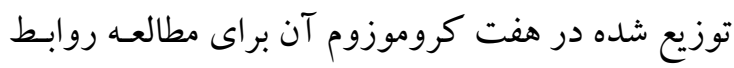

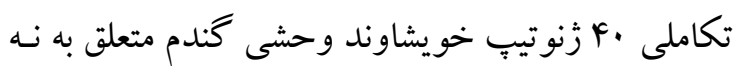

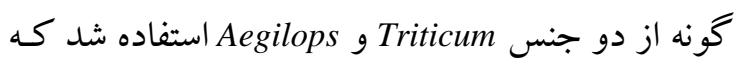

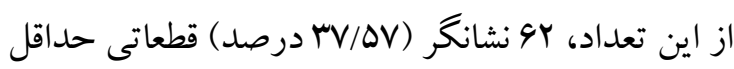

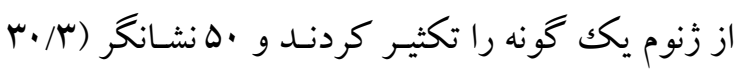

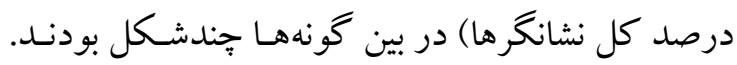

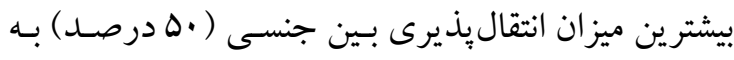

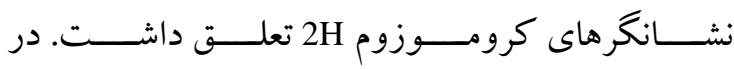

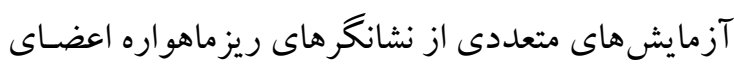

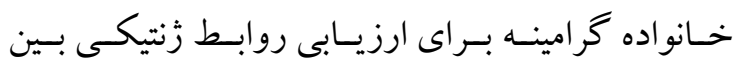
جنس ها و گونهاى مختلف استفاده شده اسـت. هـولتن

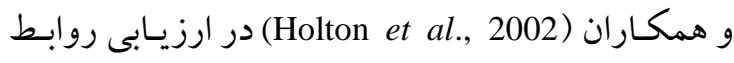

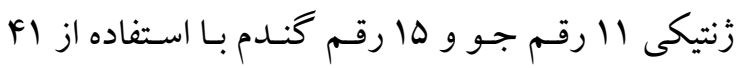

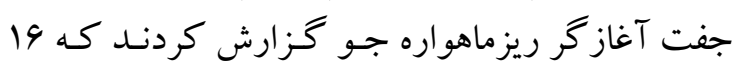

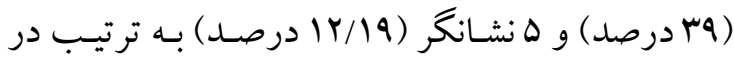

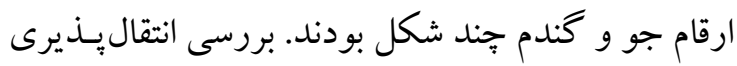

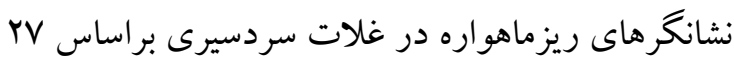

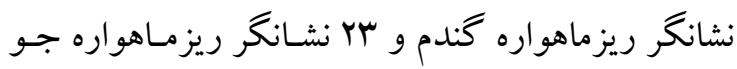


Adonina, I.G., E.A. Salina, E.G. Pestsova and M.S. Röder. 2005. Transferability of wheat microsatellites to diploid Aegilops species and determination of chromosomal localizations of microsatellites in the $\mathrm{S}$ genome. Genome 48: 959-970.

Ahn, S., J.A. Anderson, M.E. Sorrells and S.D. Tanksley. 1993. Homoeologous relationships of rice, wheat and maize chromosomes. Mol. Genet. Genomics 241: 483-490.

Andrew, H., J.E. Paterson, M.D. Bawers, X.D. Buraw, G.E. Christin and J.W. Robert. 2000. Comparative genomics of plant chromosomes. Plant Cell Rep. 12: 1523-1539.

Beales, J., A. Turner, S. Griffiths, J.W. Snape and D.A. Laurie. 2007. A pseudo-response regulator is misexpressed in the photoperiod insensitive Ppd-D1a mutant of wheat (Triticum aestivum L.). Theor. Appl. Genet. 115: 721-733.

Bennetzen, J.L. and M. Freeling. 1997. The unified grass genome: synergy in synteny. Genome. Res. 7: 301-306.

Botstein, D., R.L. White, M. Skolnick and R.W. Davis. 1980. Construction of a genetic linkage map in man using restriction fragment length polymorphisms. Am. J. Hum. Genet. 32: 314-331.

Castillo, A., G. Dorado, C. Feuillet, P. Sourdille and P. Hernandez. 2010. Genetic structure and ecogeographical adaptation in wild barley as revealed by microsatellite markers. BMC Plant Biol. 10: 266-279.

Castillo, A., H. Budak, A. C. Martin, G. Dorado, A. Borner, M. Roder and P. Hernandez. 2009. Interspecies and intergenus transferability of barley and wheat D-genome microsatellite markers. Ann. Appl. Biol. 156: 347-356.

Castillo, A., H. Budak, R.K. Varshney, G. Dorado, A. Graner and P. Hernandez. 2008. Transferability and polymorphism of barley EST-SSR markers used for phylogenetic analysis in Hordeum chilense. BMC Plant Biol. 8: 97-100.

Colmer, T. D., T. J. Flowers and R. Munns. 2006. Use of wild relatives to improve salt tolerance in wheat. J. Exp. Bot. 57: 1059-1078.

Fahima, T., M.S. Roder, A. Grama and E. Nevo. 1998. Microsatellite DNA polymorphism divergence in Triticum dicoccoides accessions highly resistant to yellow rust. Theor. Appl. Genet. 96: 187-195.

Feldman, M. and A.A. Levy. 2005. Allopolyploidy- a shaping force in the evolution of wheat genomes. Cytogenet. Genome Res. 109: 250-258.

Feuillet, C. and G.J. Muehlbauer. 2009. Genetics and Genomics of the Triticeae. Plant Genetics and Genomics. Springer.

Gororo, N.N., H.A. Hagles, R.F. Eastwood, M.E. Nicolas and R.G. Flood. 2002. Use of Triticum tauschii to improve yield of wheat in low-yielding environments. Euphytica 123: 241-254. 


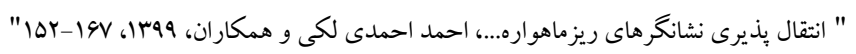

Holton, T.A., J.T. Christopher, L. McClure, N. Harker and R.J. Henry. 2002. Identification and mapping of polymorphic SSR markers from expressed gene sequences of barley and wheat. Mol. Breed. 9: 63-71.

Hovhannisyan, N.A., M.E. Dulloo, A.H. Yesayan, H. Knupffer and A. Amri. 2011. Tracking of powdery mildew and leaf rust resistance genes in Triticum boeoticum and T. urartu, wild relatives of common wheat. Czech J. Genet. Plant Breed. 47: 45-57.

Huang, S.X., A. Sirikhachornkit, X.J. Su, J. Faris, B. Gill, R. Haselkorn and P. Gornicki. 2002. Genes encoding plastid acetyl-CoA carboxylase and 3-phosphoglycerate kinase of the Triticum/Aegilops complex and evolutionary history of polyploid wheat. Proc. Nat. Acad. Sci. USA 99: 8133-8138.

Hulbert, S.H., T.E. Richter, J.D. Axtell and J.L. Bennetzen. 1990. Genetic mapping and characterization of sorghum and related crops by means of maize DNA probes. Proc. Nat. Acad. Sci. USA 87: 4251-4255.

Korzun, V., M.S. Roder, K. Wedehake, A. Pasqualone, C. Lotti, M.W. Ganal and A. Blanco. 1999. Integration of dinucleotide microsatellites from hexaploid bread wheat into a genetic linkage map of durum wheat. Theor. Appl. Genet. 98: 1202-1207.

Kuleung, C., P.S. Baenziger and I. Dweikat. 2004. Transferability of SSR markers among wheat, rye, and triticale. Theor. Appl. Genet. 108: 1147-1150.

Kurata, N., G. Moore, Y. Nagamura, T. Foote, M. Yano, Y. Minobe and M.D. Gale. 1994. Conservation of genome structure between rice and wheat. BioTechnol. 12: 276-278.

Li, J.Z., T.G. Sjakste, M.S. Roder and M.W. Ganal. 2003. Development and genetic mapping of 127 new microsatellite markers in barley. Theor. Appl. Genet. 107: 1021-1027.

Lina, M.A., Y.M. Mohammad and H. Nadia. 2012. The genetic relationships among Aegilops L. and Triticum L. species. Asian J. Agric. Sci. 4: 352-367.

Liu. K. and S.V. Muse. 2005. Power Marker: Integrated analysis environment for genetic marker data. Bioinformatics 2: 2128-2129.

Maestra, B. and T. Naranjo. 2000. Genome evolution in Triticeae. In: Olmo E., Redi C.A. (Eds.) Chromosomes Today. Birkhäuser, Basel, pp. 155-167.

Magurran, A.E. 2004. Measuring Biological Diversity. Blackwell.

Mason-Gamer, R.J. 2005. The ß-amylase genes of grasses and a phylogenetic analysis of the Triticeae (Poaceae). Am. J. Bot. 92: 1045-1058

Miki, Y., K. Yoshida, N. Mizuno, S. Nasuda, K. Sato and S. Takumi. 2019. Origin of wheat B-genome chromosomes inferred from RNA sequencing analysis of leaf transcripts from section Sitopsis species of Aegilops. DNA Res. 26(2): 171-182.

Nei, M. 1973. Analysis of gene diversity in subdivided populations. Proc. Nat. Acad. Sci. USA. 70: 3321-3323. 


$$
\text { "نشريه علوم زراعى ايران"، جلد بيست و دوم، شماره r، تابستان }
$$

Nei, M. 1978. Estimation of average heterozygosity and genetic distance from a small number of individuals. Genetics 89: 583-590.

Oliveira, E.J., J.G. Paìdua, M.I. Zucch, R. Vencovsky and M.L.C. Vieira. 2006. Origin, evolution and genome distribution of microsatellites. Genet. Mol. Res. 29: 294-307.

Peakall, R. and P. Smouse. 2012. GenAlEx 6.5: Genetic analysis in Excel. Population genetic software for teaching and research, an update. Bioinformatics 28: 2537-2539.

Pestsova, E., V. Korzun, N.P. Goncharov, K. Hammer, M.W. Ganal and M.S. Röder. 2000. Microsatellite analysis of Aegilops tauschii germplasm. Theor. Appl. Genet. 101: 100-106.

Petersen, G. and O. Seberg. 2005. Phylogenetic analysis of allopolyploid species. Czech J. Genet. Plant Breed. 41: $28-37$

Ramsay, L., M. Macaulay, D. S. Ivanissevich, K. MacLean, L. Cardle, J. Fuller, K. J. Edwards, S. Tuvesson, M. Morgante, A. Massari, E. Maestri, N. Marmiroli, T. Sjakste, M. Ganal, W. Powell and R. A. Waugh. 2000. Simple sequence repeat-based linkage map of barley. Genetics, 156: 1997-2005.

Röder, M.S., J. Plaschke, S.U. Konig, A. Borner, M.E. Sorrells, S.D. Tanksley and M.W. Ganal. 1995. Abundance, variability and chromosomal location of microsatellites in wheat. Mol. Gen. Genet. 246: 327-333.

Rodriguez-Suarez, C., M.C. Ramirez, A. Martin and S.G. Atienza. 2011. Applicability of chromosomespecific SSR wheat markers for the introgression of Triticum urartu in durum wheat breeding programmes. Plant Genet. Resour. 9: 439-444.

Safari, Z. and A.A. Mehrabi. 2019. Molecular phylogeny of Aegilops L. and Triticum L. species revealed by internal transcribed spacers of ribosomal genes. J. Agric. Sci. Technol. 21(3): 699-714.

Saghai Maroof, M.A., R.M. Biyashev, G.P. Yang, Q. Zhangf and R.W. Allard. 1994. Extraordinarily polymorphic microsatellite DNA in barley: Species diversity, chromosomal locations and population dynamics. Proc. Nat. Acad. Sci. USA 91: 5466-5470.

Schneider, A., I. Molnár and M. Molnár-Láng. 2008. Utilisation of Aegilops (goatgrass) species to widen the genetic diversity of cultivated wheat. Euphytica, 163(1): 1-19.

Sharma, S., H.S. Balyan, P.L. Kulwal, N. Kumar, R.K. Varshney, M. Prasad and P.K. Gupta. 2002. Study of interspecific SSR polymorphism among 14 species from Triticum-Aegilops group. Wheat Info. Serv. 95: 23-28.

Sourdille, P., M. Tavaud, G. Charmet and M. Bernard. 2001. Transferability of wheat microsatellites to diploid Triticeae species carrying the A, B and D genomes. Theor. Appl. Genet. 103: 346-352.

Tamura, K., D. Peterson, N. Peterson, G. Stecher, M. Nei and S. Kumar. 2011. MEGA5: Molecular evolutionary genetics analysis using maximum likelihood, evolutionary distance, and maximum parsimony methods. Mol. Biol. Evol. 28(10): 2731-2739. 


$$
\text { " انتقال يذيرى نشانكرهاى ريزماهو اره.... احمد احمدى لكى و همكاران، 1OY-19V IT99، }
$$

Tilman, D., C. Balzer, J. Hill and B. L. Belfort. 2011. Global food demand and the sustainable intensification of agriculture. Proc. Nat. Acad. Sci. USA 108: 20260-20264.

Varshney, R.K., R. Sigmund, A. Börner, V. Korzun, N. Stein, M.E. Sorrells, P. Langridge and A. Graner. 2005. Interspecific transferability and comparative mapping of barley EST-SSR markers in wheat, rye and rice. Plant Sci. 168: 195-202.

Yildirim, A., N. Kandemir, O. Ates Sonmezoglu and T. Eserkaya Gulec. 2009. Transferability of microsatellite markers among cool season cereals. Biotechnol. Biotechnol. Equip. 23: 1299-1302.

Zhang, L. 2006. Study of the transferability of microsatellite markers derived from bread wheat (T. aestivum) or rice (O. sativa) ESTs (EST-SSRs) to their close and wild relative and evaluation of their potential for the organization of genetic resources in the grass family. Vegetal Biology, Universite Blaise Pascal. 
"نشريه علوم زراعى ايران"، جلد بيست و دوم، شماره r، تابستان 99سا

\title{
Transferability of barley microsatellite markers for assessing genetic relationships of wheat wild relatives of Triticum and Aegilops genera
}

\author{
Ahmadi Laki, A. ${ }^{1}$, S. A. Mohammadi ${ }^{2}$, M. Moghaddam ${ }^{3}$ and M. Valizadeh ${ }^{4}$
}

\begin{abstract}
Ahmadi Laki, A., S. A. Mohammadi, M. Moghaddam and M. Valizadeh. 2020. Transferability of barley microsatellite markers for assessing genetic relationships of wheat wild relatives of Triticum and Aegilops genera. Iranian Journal of Crop Sciences. 22(2): 152-167. (In Persian).
\end{abstract}

Comparative genomics has revealed a high degree of collinearity between related species, which allows transferability of interspecies and intergenus markers. The aim of this study was to examine the transferability of barley microsatellite markers among species of Triticum and Aegilops genus for determination of their genetic relationships. The experiments was carried out in faculty of agriculture, university of Tabriz, Iran, in 2016. Among 165 evaluated barley microsatellite primer pairs in 40 genotypes from nine species of Triticum and Aegilops genus, $62(37.57 \%)$ showed successful amplification at least in the genome of one species and 50 (30.3\%) were polymorphic. Using 50 polymorphic primer pairs, 223 alleles were amplified and number of alleles varied from 2 to 14 with an average of 4.46. The mean of polymorphic information content and genetic diversity were 0.55 and 0.6 , respectively. The studied genotypes were assigned into four groups using NieghborJoining clustering algorithm and Guckes Cantor evolutionary distance coefficient. The species of Triticum and Aegilops genera were grouped separately, and within each genus, grouping was in accordance with their genome structure. In principal coordinate analysis, two first coordinates explained 24.63 and $21.86 \%$ of molecular variation, respectively, and distribution of the genotypes based on two first coordinates was in concordance with grouping of cluster analysis. The results indicated that the transferable barley markers could be successfully utilized in wheat and its wild relatives genetics and breeding studies.

Key words: Barley, Genetic diversity, SSR markers, Transferability and Wheat wild relatives.

\footnotetext{
Received: June, $2019 \quad$ Accepted: July, 2020

1. Former MSc Student, University of Tabriz, Tabriz, Iran

2. Professor, University of Tabriz, and Center of Excellence in Cereals Molecular Breeding, University of Tabriz, Tabriz, Iran (Corresponding author) (Email: mohammadi@tabrizu.ac.ir)

3. Professor, University of Tabriz, and Center of Excellence in Cereals Molecular Breeding, University of Tabriz, Tabriz, Iran

4. Professor, University of Tabriz, and Center of Excellence in Cereals Molecular Breeding, University of Tabriz, Tabriz, Iran
} 